\title{
Classification of Fall Detection System for Elderly: Systematic Review
}

\author{
Ainul Husna Mohd Yusoff*1, Salihatun Md Salleh ${ }^{* 2}$,Izzuddin Zaman³, Waluyo Adi Siswanto ${ }^{4}$ \\ 1,2,3 Faculty of Mechanical and Manufacturing Engineering, Universiti Tun Hussein Onn Malaysia, \\ Johor, Malaysia \\ ${ }^{4}$ Faculty of Mechanical and Manufacturing Engineering, Universitas Muhammadiyah Surakarta, \\ Central Java, Indonesia \\ E-mail: ${ }^{2 *}$ saliha@uthm.edu.my
}

Article History: Received: 10 November 2020; Revised: 12 January 2021; Accepted: 27 January 2021; Published online: 05 April 2021 Abstract: Elderly are the world's largest growing population, categorized over the age of 60 to 65 years. They are the ones
who prone to fall due to their old age and low self-efficacy, thus making them vulnerable to different accidents. Even doing
daily activities can also expose the elderly to a fall incident. As a result, it has gained the attention of many researchers in
conducting studies related to the elderly daily health care, especially in relation to the fall detection system. This paper aims
to provide a systematic review on the classification of fall detection systems for the elderly. This systematic review is
designed based on the existing and extensive literature review on fall detection systems guided by the prisma statement
(preferred reporting items for systematic reviews and meta-analyses) review method. Based on this systematic review, four
overarching themes that provide in-depth information on fall detection to detect fall events have been identified; classification
of fall detection, basis development, type of sensor and detection technique. In a nutshell, the fall detection approach has
successfully provided an alternative health care services for elderly who choose to live independently. Therefore, it is
important to continue to develop a fall detection system that integrates with technology in order to provide a safe living
environment for elderly, and for children, it can offer as an alternative for monitoring systems.

Keywords:Systematic review, elderly people, fall detection, classification, detection technique

\section{Introduction}

Elderly is the most group of large population in every world country. The age of 65 years has accepted to be categorized as 'elderly' or older person by the most developed world countries, but this does not adapt well to the situation in Africa compared to the west (Kowal and Dowd, 2001). This elderly definition is somewhat arbitrary; it associated with the age where a person begins to receive pension benefits. In Britain, as far back as 1875, the definition of old age as any age after 50 enacted by the Friendly Societies Act, yet pension schemes mostly used age 60 or 65 years for eligibility (Roebuck, 1979). Hence, according to the United Nations, agreed cutoff is $60+$ years, be known as the older population, despite there is no standard rigid numerical criterion (Mirkin\& Weinberger, 2001).

The population of older people in the world is growing. According to a report presented by the Population Division of the United Nations, this trend is projected to reach $21 \%$ in 2050, increasing from only $10 \%$ in 2000 (United Nations, 2005). Since the turn of the 20th century, human society has undergone tremendous demographic changes (Foroughi et al., 2005). It shows that throughout the year, the elderly population will be the world's largest population. In terms of living lifestyle, older people often prefer to live alone with their spouse rather than living with their married children. This lifestyle unexpectedly alters the family structure and its members, causing more elderly to live alone. However, older people living alone in addition to declining health function can create a more dangerous living environment. Previous studies indicate that falls in older people are at a higher risk when they live alone (Cippitelli et al., 2017; Stone et al., 2014). Also, they become prone to different accidents at old age, so there are high risks for them living alone (Suryadevara\& Mukhopadhyay, 2012).

Falling is one of those incidents that can happen anytime and in any place. Fall is one of the most common problems faces by older people where they can involve falls in many conditions, even while doing their daily routine. One in three-person lives in the community, who over the age of 65 years, is estimated to fall one or more times each year, with the risk of falling increases with age (Tinetti, 1994; Hausdorff et al., 2001; Hwang et al., 2004; Zheng et al., 2009). This ratio rises about 50\% valid for persons over the age of 80 years (Tinetti \& Williams, 1997). Increasing age, mortality, morbidity, disability, and frailty were the factors that lead to the increase in the rate of falls (Jian \& Chen, 2015; Khan \&Hoey, 2017). Falls usually caused by the imbalance or inability to recover balance, leading to injuries, acute or chronic health conditions, and deaths (Yodpijit et al., 2017). 
Consequentially falls lead to a significant increase in healthcare costs. Falling accidents may lead to a decline in the quality of life of patients and family members as well as the impact on the society in terms of resources required for criminal justice, medical treatment, and other specific public services (Ambrose et al., 2013). When a fall occurs, it can cause severe damage to a person's health, loss of independence, no social contacts, lack of movements, decrease in productivity and fear of falling, which eventually can contribute to the risk of another possible fall (De Backere et al. 2015; Sabatini et al. 2016; Pannurat et al. 2017). Besides, falls can also exert economic pressures that lead to physiological burden and even affect the caregiver's quality of life (Faes et al., 2010; Zarit et al., 1980; Kuzuya et al., 2010). Also, it results in social isolation, which makes the quality of life lower because of loss of confidence (Luque et al. 2014). Therefore, an early response to the elderly's falls can reduce serious consequences. Hence, a solution to manage the increasing workloads of caregivers and to have a system that can be adapted to the elderly's lifestyle to provide a safe living environment is needed. The increment of the ageing population and rising cost in health care have made health monitoring become an essential part of modern life (Shang et al., 2014). In other words, the care services for the elderly were important in line with the growing elderly population.

One of the care services that the elderly needed was the sudden fall detection. Usually, when the elderly are suffering a falling event that needs medical attention, they need to ask for help by themselves. This conventional approach can have an adverse effect as it delays in getting help. Especially it can be a threat to the older people life that living alone if they encounter a fall accident where their help cannot be provided at the right time (Hsu $\&$ Chien, 2009). Therefore, there are many types of research in developing a fall detection system that acts as a guardian for the elderly. Researchers that involved in this research topic have classified the fall detection system into three categories; camera-based device, ambience device, and wearable device (Yu, 2008; Mubashir et al., 2013).

\subsection{Towards a review framework on fall detection development for elderly people}

A systematic review is an examination process formulated questions that applies systematic and explicit methods to identify selected studies to be appraised critically and to analyze data collected from the studies. In contrast to statistical methods that may or may not be utilized to analyze and extract the results of the relevant studies (Higgins et al., 2011). Through a systematic review, authors can obtain responses to identify the research gaps and direction needed for future work. The systematic review offers a great opportunity to state the significance of this research as supporting evidence that the research is still relevant to be carried out. Also, analyzing all the accessible data can determine the response to the relevant research question. Apart from that, it also encourages researchers to produce quality evidence with more significant results.

Although there has been a great deal of research being conducted on the fall detection system, efforts to review this research topic systematically are still lacking. This review paper attempts to fill the gap in reviewing and identifying different types of fall detection. Reports on the fall detection system are used as a reference, emphasizing that this study becomes a baseline overview by providing various types of fall detection development. This study fills an essential gap in the literature, with the most systematic review focusing on a narrow scope or specific category of fall-related systems. Some previous studies have only considered subfield implementation of fall-related systems (Habib et al., 2014; Zhang et al., 2015; Perry et al., 2009) or mainly provide knowledge about principles, trends and issues of the fall detection system as (Koshmak et al. (2016). Reviews on fall-related systems always emerge; however, it has evolved over the year, which makes the current trends have little in common with those that been reviewed (Noury et al., 2007; Igual et al., 2013; Rajagopalan et al., 2017). This study is critical because there is still a lack of reviewing the type of fall detection that has developed and the current state of this fall detection development. Previous systematic review articles on fall detection trends did not provide sufficient details; for example, database searched, articles excluded, search terms used. This eventually has made it difficult for future researchers to replicate and interpret the current studies comprehensively (Greenhalgh \& Peacock, 2005). Every country will experience an increase in the elderly population which will make the fall detection essential to provide a safe living environment for them. Thus, details of the peer-reviewed literature so far can provide insightful information on where the emphasis should be given and where attention should be placed.

In constructing the current systematic review, is based on the main research question - how many classifications of the fall detection system? This study will focus on the structure of a different type of fall detection system and attempt to synthesize on developed fall detection system for the elderly. Other than that, this section discusses the need to conduct a systematic review of the fall detection system. In contrast, the following section discusses the approach used to acquire the answer to the research question. The third section 
analyzes and systematically reviews the scientific literature to distinguish, select, and appraise relevant research on the fall detection system. Finally, the last section discusses the part that needs to be taken as future research priorities and the significant of conducting this systematic review.

\section{Methods}

This section describes the methods used to review and synthesize the development of a fall detection system for older people. The review uses a method called PRISMA (includes Scopus and Science Direct resources) to conduct the systematic review, inclusion and exclusion criteria, data abstraction, and analysis.

\subsection{Design}

A systematic review was designed based on existing literature on fall detection systems guided by the PRISMA statement (Preferred Reporting Items for Systematic reviews and Meta-Analyses). According to SierraCorrea \&Kintz, (2015), it offers three unique advantages which are; defining clear research questions that permits systematic research, identifies inclusion and exclusion criteria, and examines the extensive database of scientific literature in a defined time. PRISMA allows rigorous search of terms related to the fall detection approach response to the independent lifestyle of older people and its impact on and coded information in future health monitoring reviews. The methodology can be used for monitoring older people in providing a safe living environment.

\subsection{Resources}

The identified related studies for the systematic review were based on two primary journal databases; Scopus and Science Direct. Scopus is the first database used in this systematic review. It was the largest abstract and citation database of peer-reviewed literature. It also has an indexing database that was used by more than 3,000 academic, government, and corporate institutions. Scopus covers a broad research area in the fields of science, technology, medicine, social science, arts, and humanities. Science Direct, which is Elsevier, known as the modern publishing business, was founded in 1880. Science Direct is the database that helps institutions and professionals in leading knowledge in advancing science, technology, and health.

\subsection{Systematic review process}

\subsection{Identification}

There are three main phases involved in the systematic review process (See Fig. 1). The first stage is the identification, where the keywords used, is identified for the search process-relying on thesaurus and previous studies, keywords or synonyms related to this study, followed by developing search strings on Scopus and Science Direct database (Refer to Table 1). The first stage of the searching process successfully retrieved a total of 799 articles from both databases.

Table 1.The search string to use in the systematic review process.

\begin{tabular}{ll}
\hline Databases & Keywords used \\
\hline \multirow{3}{*}{ Scopus } & $\begin{array}{l}\text { TITLE-ABS-KEY( ( "fall detector" OR "fall detection" ) AND ( "elderly" OR } \\
\text { "old" OR "aged" OR "aging" OR "retired" OR "senior citizen" ) AND (elderly } \\
\text { care) })\end{array}$ \\
& $\begin{array}{l}\text { ( "fall detector" OR "fall detection" ) AND ( "elderly" OR "old" OR "aged" } \\
\text { Science Direct }\end{array}$ \\
& OR "aging" OR "retired" OR "senior citizen" ) AND (elderly care)
\end{tabular}




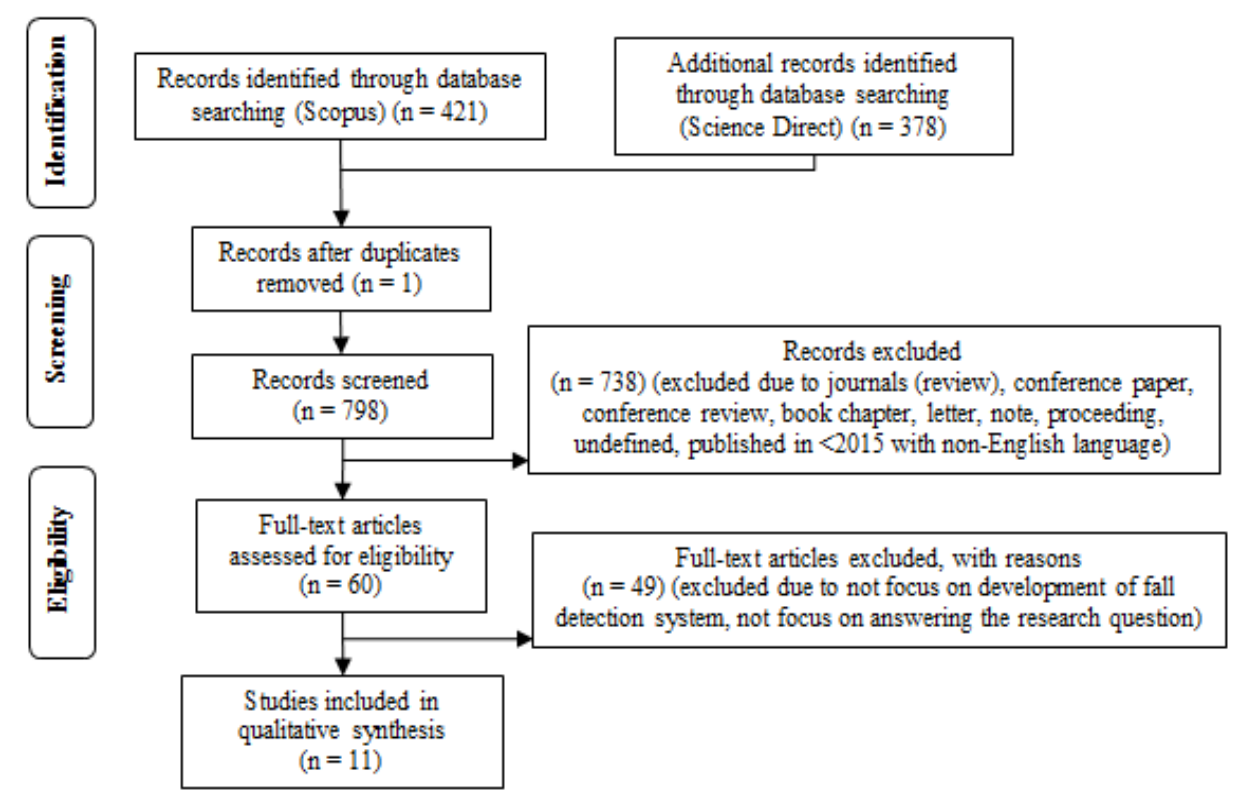

Figure 1.PRISMA method process in this study adapted from Moher et al. (2010).

\subsection{Screening}

The purpose of the first screening stage is to eliminte a duplicated article. At this screening stage, one duplicated article was removed. While 798 articles were screened by accessing the full articles, and the articles were excluded by the researcher in the second stage based on the exclusion criteria as in Table 2. Literature type was the first criterion in which the researchers decided to focus on the journal (research articles) only due to it provides empirical data that acts as a primary source. Therefore, this implies that systematic review, conference review, book, book chapter, letter, a proceeding was excluded in this current research. Besides, it should be noted that the review only focused on articles that were published in English. Moreover, it is crucial that the chosen year coverage for this review was four years (2015-2019). Hence, a total of 738 articles were excluded based on these criteria (Refer to Table 2).

Table 2. The inclusion and exclusion criteria

\begin{tabular}{lll}
\hline Criterion & Eligibility & Exclusion \\
\hline Literature type & Journal (research article) & $\begin{array}{l}\text { Journals (review), conference paper, conference } \\
\text { review, book chapter, letter, note, proceeding, } \\
\text { undefined } \\
\text { less than 2015 }\end{array}$ \\
Timespan & Between 2015-2019 & Non-English \\
Language & English & \\
\hline
\end{tabular}

\subsection{Eligibility}

The third stage is the eligibility stage. A total of 60 articles were prepared for this stage. At this stage, the full paper must be accessed, titles, abstract, and content were examined thoroughly to ensure it fit to be employed in this study. Consequently, a total of 49 articles were excluded because there are discovered to not focus on the development of the fall detection system and not based on empirical data. The final stage reviewed resulted in a total of 11 articles that were used to be extracted and analyzed.

\subsection{Data abstraction and analysis}

The selected articles were accessed fully and analyzed. Efforts were concentrated on specific studies that responded to the engaged research question. The articles were extracted starting from the abstracts, then continue in-depth the full article to identify related themes and sub-themes. All these included studies were summarized and synthesized, as in Table 3. 


\section{RESULTS}

\subsection{General findings and characteristics of the study included in the review}

The analysis produced a total of four themes, three sub-themes related to the classification of the fall detection system. The four themes are classification of fall detection, basis development, type of sensor, and detection technique. The results provided a comprehensive analysis of the classification of the various fall detection system and the advantages or limitations of the developed fall detection system. More specifically, it should be noted that there is one study about real-time fall detection practices originated from the United States of America (Serpen\& Khan, 2018), and one study originated from Spain (Yacchirema et al., 2018). One study that has basis development by using a conventional device (Soewito et al., 2015) which originated from Indonesia and one study from Brazil (Rodrigues et al., 2018). A total of two studies conducted in Japan (Kong et al., 2018; Sumiya et al., 2015) practice image analysis in detecting fall events and one study originated from Taiwan (Lu \& Chu, 2018).

While there is one study from China using 3D depth image analysis (Yang et al., 2016), three studies focused on development fall detection system-based sensor instalment. Two studies concentrated on the placement of the sensor on a wall (Rantz et al., 2015; Asbjørn\& Jim, 2017) originated from Columbia and Norway, while another one study focuses on the sensor placement designed as a floor mat which originated from Malaysia (Kumar et al., 2018) was also included in the review. In the case of the present study, regarding the year of publication, three articles were published in 2015 (Soewito et al., 2015; Sumiya et al., 2015; Rantz et al., 2015), one article was published in 2016 (Yang et al., 2016), and was another one published in 2017 (Asbjørn\& Jim, 2017), and six studies were published in 2018 (Serpen\& Khan, 2018; Yacchirema et al., 2018; Rodrigues et al., 2018; Kong et al., 2018; Kumar et al., 2018; Lu \& Chu, 2018).

Table 3.Summarized of included papers.

\begin{tabular}{|c|c|c|c|c|c|c|}
\hline 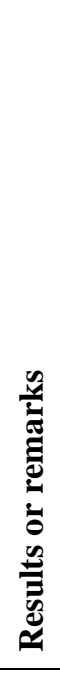 & 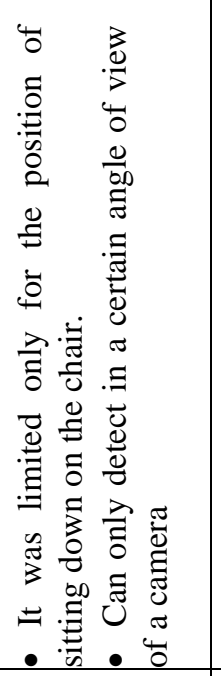 & 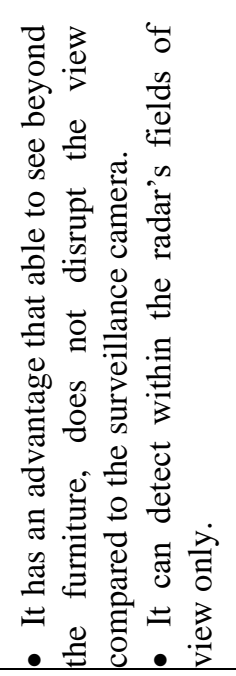 & 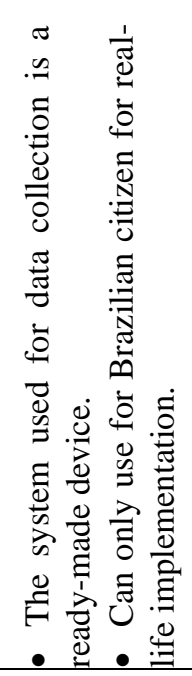 & 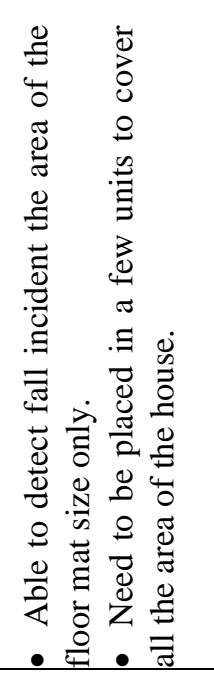 & 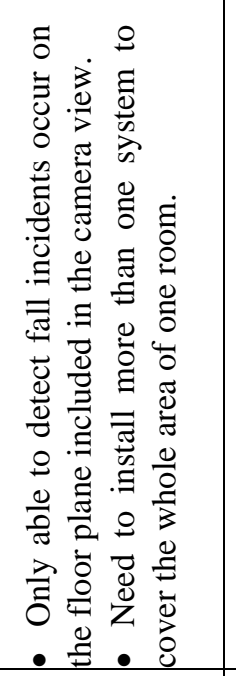 & 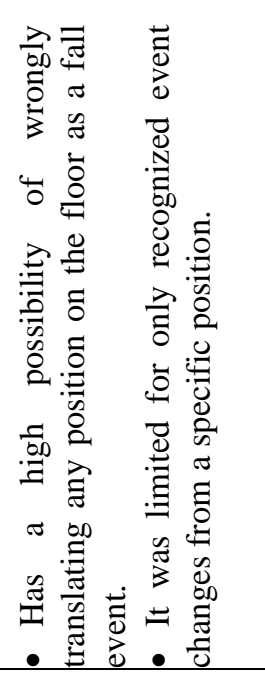 \\
\hline 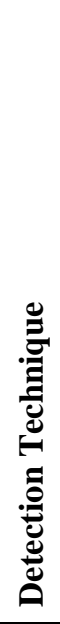 & 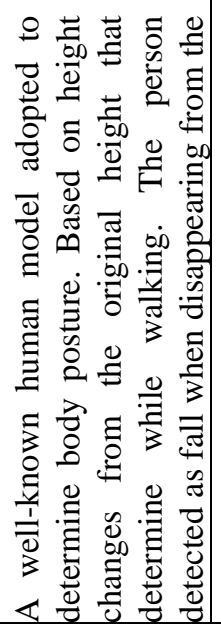 & 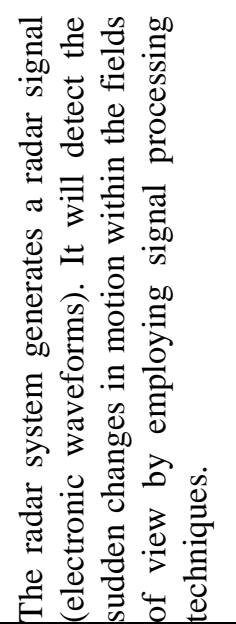 & 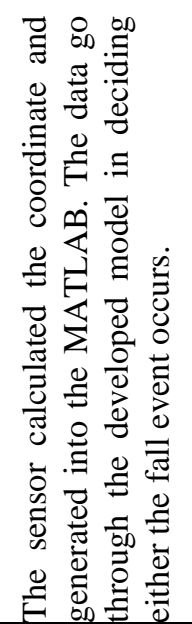 & 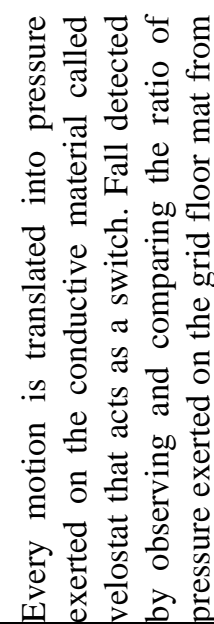 & 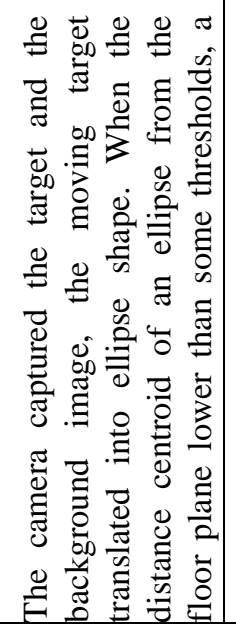 & 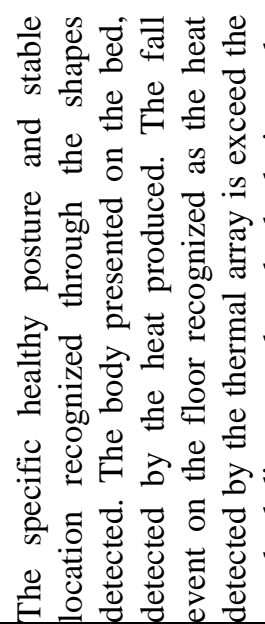 \\
\hline
\end{tabular}




\begin{tabular}{|c|c|c|c|c|c|c|}
\hline 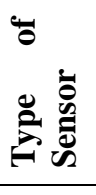 & 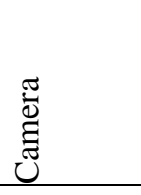 & 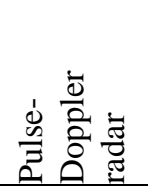 & 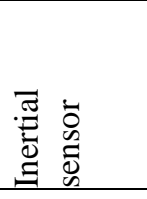 & $\begin{array}{l}\stackrel{0}{N} \\
\stackrel{0}{2}\end{array}$ & 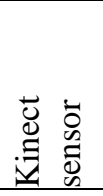 & 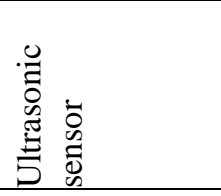 \\
\hline 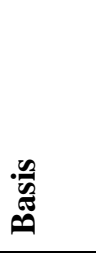 & 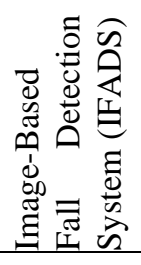 & 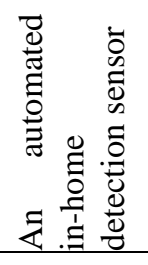 & 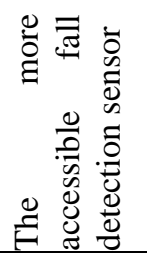 & 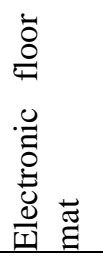 & 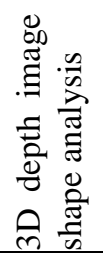 & 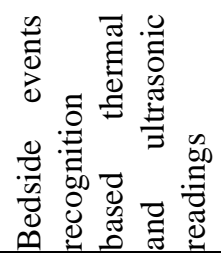 \\
\hline 己̈ & 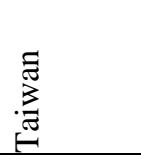 & 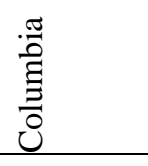 & 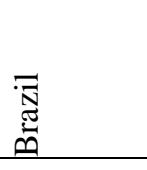 & $\frac{. \frac{\pi}{2}}{\frac{\pi}{\pi}}$ & 前 & 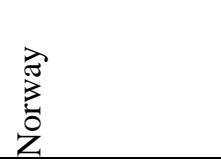 \\
\hline 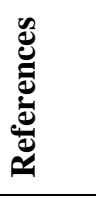 & 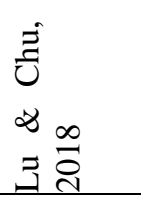 & 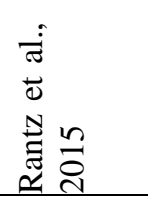 & 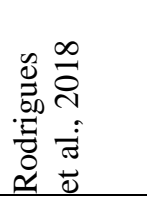 & 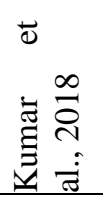 & 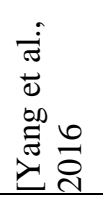 & 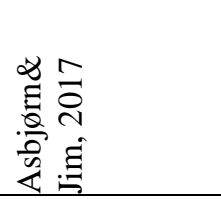 \\
\hline
\end{tabular}

Table 3. (continued).

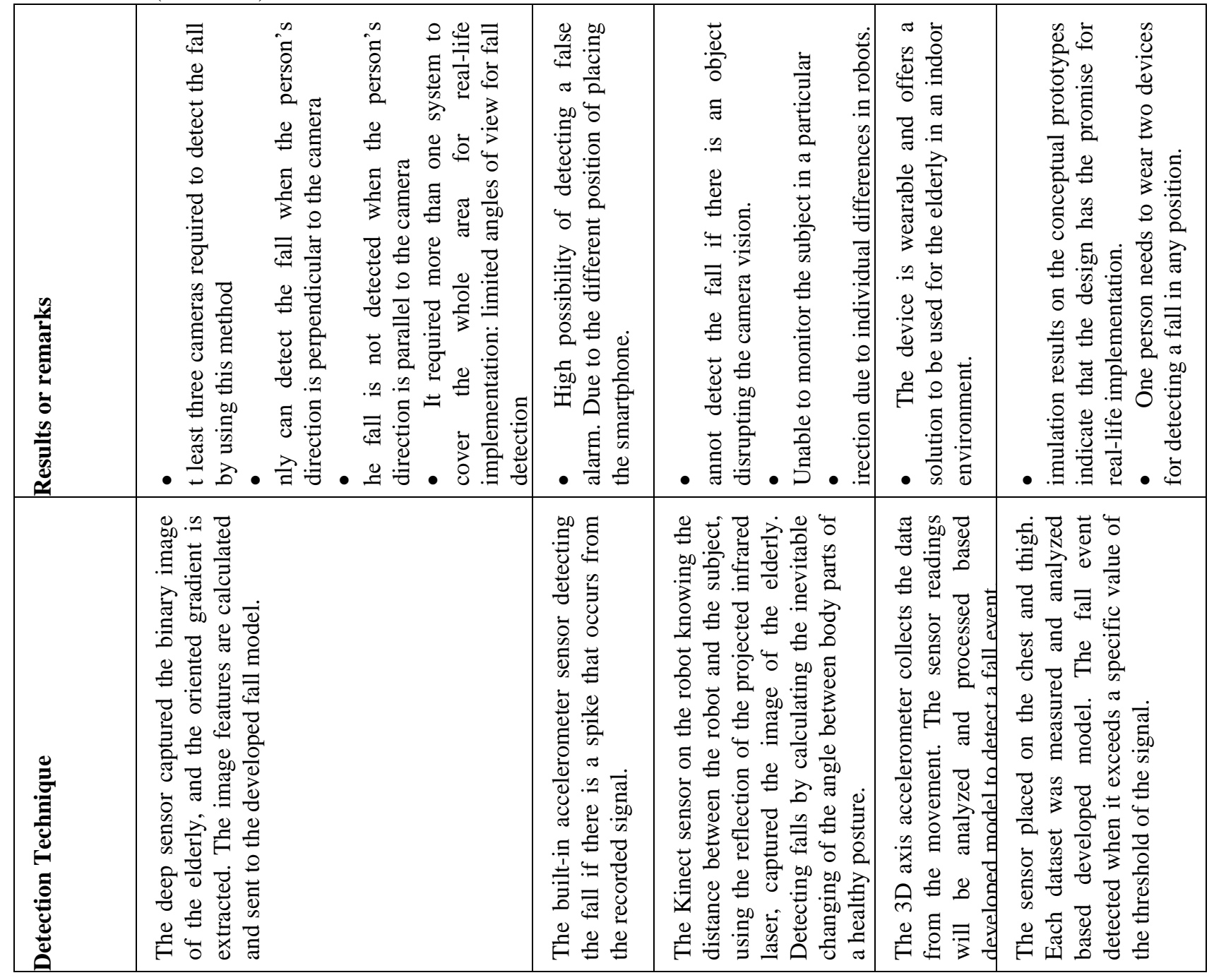




\begin{tabular}{|c|c|c|c|c|c|}
\hline 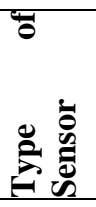 & 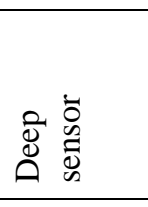 & 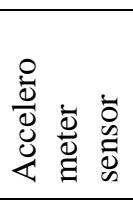 & 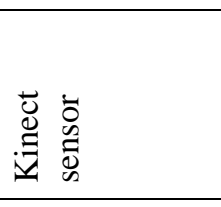 & 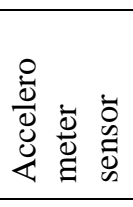 & 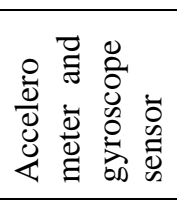 \\
\hline 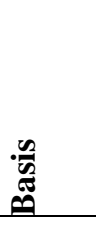 & 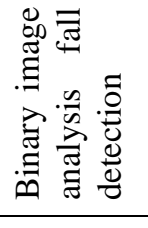 & 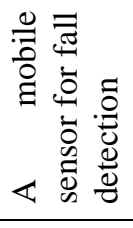 & 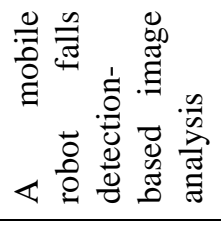 & 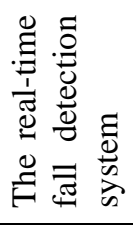 & 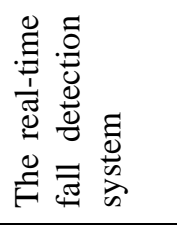 \\
\hline$\vec{\Xi}$ & $\begin{array}{l}\text { :్ } \\
\text { 壳 }\end{array}$ & 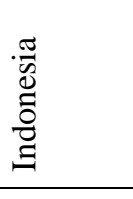 & 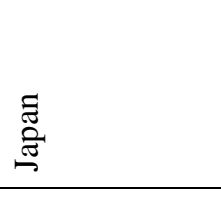 & $\begin{array}{l}\text {. } \\
\text { की }\end{array}$ & 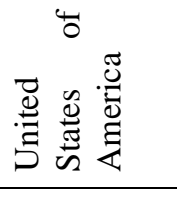 \\
\hline 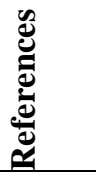 & 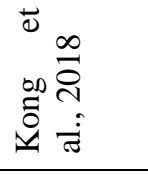 & 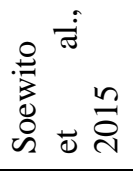 & 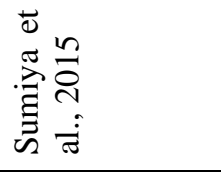 & 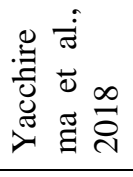 & 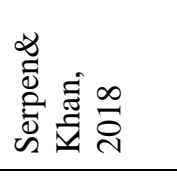 \\
\hline
\end{tabular}

\subsection{Classification and type of sensor of the fall detection system}

The classification of the fall detection system categorized into three classifications, which consisted of visionbased, ambient based, and wearable devices. Total of four studies classified as vision-based fall detection that utilized camera, Kinect sensor, a deep sensor such as RGB camera that analyzed from the image, 3D image or video captured through the camera (Lu Chu, 2018; Kong et al., 2018; Yang et al., 2016; Sumiya et al., 2015). Three studies classified as an ambient based fall detection system, which used pulse-doppler radar attached on the wall (Rantz et al., 2015), an electronic floor mat that attached with a piezo sensor (Kumar et al., 2018).

Also, one study using an ultrasonic sensor attached to the ceiling (Asbjørn\& Jim, 2017). Four studies issued under the wearable device. One study using a device developed by using accelerometer, gyroscope sensor (Yacchirema et al., 2018) and three studies using a built-in sensor from a conventional device (Soewito et al., 2015; Serpen\& Khan, 2018; Rodrigues et al., 2018) (see Table 4).

Table 4. The central theme and sub-themes

\section{Classificatio}

n of the fall Authors

detection

$\begin{array}{llllllllllll}\text { Lu } & \text { Rant } & \text { Rodrigue } & \text { Kuma } & \text { Yan } & \text { Asbjørn } & \text { Kon } & \text { Soewit } & \text { Sumiy } & \text { Yacchirem } & \text { Serpen } \\ \& & \text { z et } & \text { s et al., } & \text { r et } & \text { g et } & \text { \& Jim, } & \text { g et } & \text { o et al., } & \text { a et al., } & \text { a et } & \text { al., } & \text { \& } \\ \text { Chu, } & \text { al., } & 2018 & \text { al., } & \text { al., } & 2017 & \text { al., } & 2015 & 2015 & 2018 & & \text { Khan, } \\ 201 & 2015 & & 2018 & 2016 & & 2018 & & & & & 2018 \\ 8\end{array}$

8

Vision-based $\sqrt{ }$

$\sqrt{ } \sqrt{ } \quad \sqrt{ }$

\section{Ambient}

based

$\sqrt{ } \sqrt{ }$

Wearable device

$\sqrt{ } \quad \sqrt{ }$

$\sqrt{ } \quad \sqrt{ } \quad \sqrt{ }$

\subsection{Detection technique}

The system's detection techniques varied from different classification and even using the same sensor. The detection techniques can be categorized by following the three classifications of the fall detection system. Four studies under the vision-based classification; one study detects a fall event by capturing the image and compared with the original image with an original posture. The fall even detected when the subject disappearing from the scope of view of the surveillance camera (Lu \& Chu, 2018). While the other study detects the fall by calculating the image features captured and the extracted oriented gradient of the binary image of the elderly (Kong et al., 2018) and another two study from (Yang et al., 2016) also involving calculation, but in a different way which the 
captured moving target was translated into ellipse shape and calculate the distance centroid of an ellipse from the floor plane. If the distance is lower than some thresholds, the motion will be detected as a fall. While a study from (Sumiya et al., 2015) measuring the distance between the robot and the subject, using the reflection of the projected infrared laser. The inevitable changing of the angle between body parts of a healthy posture will be calculated in detecting a fall event.

There are three studies under ambient based classification that also have a different way of detection technique even under the same category. One study detecting the sudden changes in motion within the fields of view by employing signal processing techniques. The detection will be observed from the radar signal generates by the radar system (Rantz et al., 2015). While, a study from (Kumar et al., 2018) detected a fall by observing and comparing the ratio of pressure exerted on the grid floor mat from the healthy posture by translating every motion into pressure exerted on the conductive material called velostat that acts as a switch. Another study detecting falls by recognizing the specific healthy posture and stable location through the shapes detected. When the heat detected by the thermal array exceeds the standard distance when the body is on the bed, which means the heat is recognized on the floor (Asbjørn\& Jim, 2017).

Another classification was the wearable device, which consists of four studies. One study from (Rodrigues et al., 2018) used the conventional device, the sensor calculated the coordinate and generated into the MATLAB. The data go through the developed model in deciding either the fall event occurs. While two studies are detecting falls by adopted the developed model. The sensor collects the data from the movement. The fall event detected as the sensor readings analyzed and processed based developed model. When the readings exceed a specific value of the threshold of the signal, it is detected as a fall (Yacchirema et al., 2018; Serpen\& Khan, 2018). Another study using a built-in sensor from a mobile device where it is detecting the fall, if there is a spike, occurs from the recorded signal. (Soewito et al., 2015).

\section{Discussion}

This study attempts to systematically analyze the existing literature on fall detection practices for the elderly. Increasing of the elderly population is a global challenge, so an assistive initiative system must be adopted to provide a safe living environment and minimize the severe effects of falls on the elderly. The rigorous review of two databases has resulted in 11 articles related to fall detection practices for the elderly. The results show that various country has engaged in a diversity of fall detection practices. Within the scope of this review, four themes have emerged. Vision-based, ambient based, and wearable devices are three main adaptation classification practices by researchers.

The review of the developed fall detection systems is summarized in the following categories: (1) advantages of the developed system, (2) reliability for real-life practices, and (3) limitation of the fall detection system. It has been noted that not all researchers use the same approach to develop fall detection. Most of the studies utilize the vision-based and wearable device as the chosen classification to develop the fall detection system.

Vision-based fall detection has the advantage of capturing the real data in a 3D image to detect falls. Since the elderly are at high risk of falling while living alone, the surveillance system shows a guarantee for investment as an alternative to monitoring the elderly. A study from Kong et al. (2017), stated that vision-based fall detection system provides a better approach since the elderly do not need to wear any devices. Also, it is promising because the elderly do not have to be engaged with technology. They do not need to operate or wear the device; they just need a camera to keep an eye on the elderly all the time. There are also studies of the elderly who have barriers to engagement with technology, and they need a learning process to adopt technology in their lives (Vaportzis et al., 2017).

Many works have been proposed to reduce injuries to fallen elderly. However, it still has some limitations where it cannot detect the subject if objects are disrupting the view of the camera, such as furniture or household items. The implementation in a real-life is quite challenging because a single camera can only cover one viewing angle. It can only detect falls when the subject's direction is perpendicular to the camera. As a result, many cameras need to be installed in a building or house to monitor the elderly at all times.

Another widely used approach is a wearable device that consists of a mobile device and a custom-made device. Fall detection that was typically using a mobile device uses accelerometers as the primary sensor. This is because an accelerometer is a useful tool in conducting mechanism of measuring the acceleration of different part of the body (Delahoz et al., 2014), as well as for recognition of daily human activity (Lara et al., 2012; Jaimes et al., 2015; Jaimes et al., 2016). It has the advantage of detecting falls at any time and anywhere as long 
as the sensor is attached to the user. However, it still requires improvement in detection accuracy as it may detect false alarms due to various position of placing the sensor on mobile devices. Simulation results on a conceptual prototype indicate that the design has the potential for real-life implementation.

Another approach under the category of a wearable device is smartphones. Smartphones always have built-in sensors and microprocessors, which makes smartphones can also be served as a platform for detecting human fall. A review from Casilari et al. (2015) stated that smartphones also have limited usability and challenges in terms of the actual applicability of Android devices. For example, the sampling frequency setting of the built-in sensors, position placement of the Android devices, and battery consumption.

Three studies used an ambient-based fall detection approach. The use of radar with an array sensor-based has the advantage of monitoring the subject anywhere as it was able to see beyond the furniture. There have been studies from other researchers (Taniguchi et al., 2014; Fan et al., 2017; Sixsmith \& Johnson et al., 2004) that support the implementation of this system to provide a safe living for the elderly in an indoor environment at all time. However, it also has a limitation in the viewing angle for monitoring. The approaches for measuring distance by detecting the presence of subjects from sensors also have a high probability of fall detection errors because it may detect regular activity such as walking from that place as a fall. Besides, the sensor attachment on the floor also has a high possibility of misinterpreting any position on the floor as a fall event. Hence, it is challenging to implement this approach in real life as it still needs improvement in detection accuracy, and many sensors need to be installed to cover the whole area of the house.

\subsection{Strength and limitations}

This systematic review focuses on specific areas, such as the classification of existing fall detection for the elderly and the synthesis of the detection techniques of the systems. Comparing the results of the studies was challenging due to the different research designs, approaches, and outcomes measures. Therefore, a metaanalysis not performed in this review. Instead, the narrative summary was performed for the heterogeneous nature of the studies.

\section{Conclusion}

This systematic review has provided insightful information on the current practice of fall detection systems for the elderly. Within the review context, an increase in the elderly population, elderly independent living style, and an increase in medical costs led to the development of a fall detection system. The review has identified the classification of fall detection from the analysis, type of sensor used, and detection technique. The number of studies related to fall detection is still increasing throughout the year. Literature has pointed out that the development of fall detection systems is still yet reliable in real-life implementation and still requires improvement in detection accuracy. Therefore, it is important that continuing to develop a fall detection system needs to be integrated with technology, provide a secure living environment for older people and children, offering an alternative to monitoring systems. This systematic review supports the potential of this device in producing a safe living environment for the elderly. Also, it provides insightful information for biomedical engineers, clinicians, and researchers to provide supporting further evidence to evaluate the real potential of each fall detection system.

\section{Acknowledgements}

The authors would like to express their gratitude to Universiti Tun Hussein Onn Malaysia (UTHM) for the financial support for this project.

\section{References}

1. Ambrose, A. F., Paul, G., \&Hausdorff, J. M. (2013). Risk factors for falls among older adults: a review of the literature. Maturitas, 75(1), 51-61.

2. Asbjørn, D., \& Jim, T. (2017). Recognizing bedside events using thermal and ultrasonic readings. Sensors, 17(6), 1342.

3. Casilari, E., Luque, R., \&Morón, M. J. (2015). Analysis of android device-based solutions for fall detection. Sensors, 15(8), 17827-17894.

4. Cippitelli, E., Fioranelli, F., Gambi, E., \&Spinsante, S. (2017). Radar and RGB-depth sensors for fall detection: A review. IEEE Sensors Journal, 17(12), 3585-3604. 
5. De Backere, F., Ongenae, F., Van Den Abeele, F., Nelis, J., Bonte, P., Clement, E., \& De Turck, F. (2015). Towards a social and context-aware multi-sensor fall detection and risk assessment platform. Computers in biology and medicine, 64, 307-320.

6. Delahoz, Y. S. \& Labrador, M. A. (2014). Survey on fall detection and fall prevention using wearable and external sensors. Sensors, 14(10), 19806-19842.

7. Faes, M. C., Reelick, M. F., Joosten-WeynBanningh, L. W., Gier, M. D., Esselink, R. A., \& Olde Rikkert, M. G. (2010). Qualitative study on the impact of falling in frail older persons and family caregivers: foundations for an intervention to prevent falls. Aging \& mental health, 14(7), 834-842.

8. Fan, X., Zhang, H., Leung, C., \& Shen, Z. (2017, November). Robust unobtrusive fall detection using infrared array sensors. In 2017 IEEE International Conference on Multisensor Fusion and Integration for Intelligent Systems (MFI), 194-199.

9. Foroughi, H., Aski, B. S., \&Pourreza, H. (2008). Intelligent video surveillance for monitoring fall detection of elderly in home environments. In 2008 11th international conference on computer and information technology, 219-224.

10. Greenhalgh, T., \& Peacock, R. (2005). Effectiveness and efficiency of search methods in systematic reviews of complex evidence: audit of primary sources. Bmj, 331(7524), 1064-1065.

11. Habib, M. A., Mohktar, M. S., Kamaruzzaman, S. B., Lim, K. S., Pin, T. M., \& Ibrahim, F. (2014). Smartphone-based solutions for fall detection and prevention: challenges and open issues. Sensors, 14(4), 7181-7208.

12. Hausdorff, J. M., Rios, D. A., \&Edelberg, H. K. (2001). Gait variability and fall risk in communityliving older adults: a 1-year prospective study. Archives of physical medicine and rehabilitation, 82(8), 1050-1056.

13. Higgins, J. P., Altman, D. G., Gøtzsche, P. C., Jüni, P., Moher, D., Oxman, A. D., \& Sterne, J. A. (2011). The Cochrane Collaboration's tool for assessing risk of bias in randomised trials. Bmj, 343, 5928.

14. Hsu, C. C., \& Chien, Y. Y. (2009). An intelligent fuzzy affective computing system for elderly living alone. In 2009 Ninth International Conference on Hybrid Intelligent Systems, 1, 293-297.

15. Hwang, J. Y., Kang, J. M., Jang, Y. W. \& Kim, H. C. (2004). Development of novel algorithm and realtime monitoring ambulatory system using Bluetooth module for fall detection in the elderly. In The 26th Annual International Conference of the IEEE Engineering in Medicine and Biology Society, 1, 22042207.

16. Igual, R., Medrano, C., \& Plaza, I. (2013). Challenges, issues and trends in fall detection systems. Biomedical engineering online, 12(1), 66.

17. Jaimes, L. G., \& Vergara-Laurens, I. J. (2015). CORREDOR, A mobile Human-Centric Sensing System for Activity Recognition. In LAWC@ LATINCOM, 36-39.

18. Jaimes, L. G., De La Hoz, Y., Eggert, C., Vergara-Laurens, I. J. (2016). Pat: A power-aware decision tree algorithm for mobile activity recognition. In 2016 13th IEEE Annual Consumer Communications \& Networking Conference (CCNC), 54-59.

19. Jian, H., \& Chen, H. (2015). A portable fall detection and alerting system based on k-NN algorithm and remote medicine. China Communications, 12(4), 23-31.

20. Khan, S. S., \&Hoey, J. (2017). Review of fall detection techniques: A data availability perspective. Medical engineering \& physics, 39, 12-22.

21. Kong, X., Meng, Z., Nojiri, N., Iwahori, Y., Meng, L., \& Tomiyama, H. (2019). A hog-SVM based fall detection IoT system for elderly persons using deep sensor. Procedia computer science, 147, 276-282.

22. Kong, X., Meng, L., \& Tomiyama, H. (2017). Fall detection for elderly persons using a depth camera. In 2017 International Conference on Advanced Mechatronic Systems (ICAMechS), 269-273.

23. Kowal, P., \& Dowd, J. E. (2001). Definition of an older person. Proposed working definition of an older person in Africa for the MDS Project. World Health Organization, 10(2.1), 5188-9286.

24. Koshmak, G., Loutfi, A., \& Linden, M. (2016). Challenges and issues in multisensor fusion approach for fall detection. Journal of Sensors, 1-12.

25. Kumar, V., Yeo, B. C., Lim, W. S., Raja, J. E., \& Koh, K. B. (2018). Development of electronic floor mat for fall detection and elderly care. Asian Journal of Scientific Research, 11, 344-356.

26. Kuzuya, M., Masuda, Y., Hirakawa, Y., Iwata, M., Enoki, H., Hasegawa, J., \& Iguchi, A. (2006). Falls of the elderly are associated with burden of caregivers in the community. International Journal of Geriatric Psychiatry: A Journal of the psychiatry of late-life and allied sciences, 21(8), 740-745.

27. Lara, O. D., \& Labrador, M. A. (2012). A survey on human activity recognition using wearable sensors. IEEE communications surveys \& tutorials, 15(3), 1192-1209.

28. Lu, K. L., \& Chu, E. T. H. (2018). An image-based fall detection system for the elderly. Applied Sciences, 8(10), 1-31. 
29. Luque, R., Casilari, E., Morón, M. J., \& Redondo, G. (2014). Comparison and characterization of android-based fall detection systems. Sensors, 14(10), 18543-18574.

30. Moher, D., Liberati, A., Tetzlaff, J., \& Altman, D. G. (2010). Preferred reporting items for systematic reviews and meta-analyses: the PRISMA statement. Int J Surg, 8(5), 336-341.

31. Mubashir, M., Shao, L., \& Seed, L. (2013). A survey on fall detection: Principles and approaches. Neurocomputing, 100, 144-152.

32. Noury, N., Fleury, A., Rumeau, P., Bourke, A. K., Laighin, G. O., Rialle, V., \& Lundy, J. E. (2007). Fall detection-principles and methods. In 2007 29th Annual International Conference of the IEEE Engineering in Medicine and Biology Society, 1663-1666.

33. Pannurat, N., Thiemjarus, S., \&Nantajeewarawat, E. (2017). A hybrid temporal reasoning framework for fall monitoring. IEEE Sensors Journal, 17(6), 1749-1759.

34. Perry, J. T., Kellog, S., Vaidya, S. M., Youn, J. H., Ali, H., \& Sharif, H. (2009). Survey and evaluation of real-time fall detection approaches. In 2009 6th International Symposium on High Capacity Optical Networks and Enabling Technologies (HONET), 158-164.

35. Rajagopalan, R., Litvan, I., \& Jung, T. P. (2017). Fall prediction and prevention systems: recent trends, challenges, and future research directions. Sensors, 17(11), 2509.

36. Rantz, M., Skubic, M., Abbott, C., Galambos, C., Popescu, M., Keller, J., \& Petroski, G. F. (2015). Automated in-home fall risk assessment and detection sensor system for elders. The Gerontologist, 55(1), 78-87.

37. Rodrigues, T. B., Salgado, D. P., Cordeiro, M. C., Osterwald, K. M., Teodiano Filho, F. B., de Lucena Jr, V. F., \& Murray, N. (2018). Fall detection system by machine learning framework for public health. Procedia Computer Science, 141, 358-365.

38. Roebuck, J. (1979). When does" old age begin?: The evolution of the English definition. Journal of Social History, 12(3), 416-428.

39. Sabatini, A. M., Ligorio, G., Mannini, A., Genovese, V., \& Pinna, L. (2015). Prior-to-and post-impact fall detection using inertial and barometric altimeter measurements. IEEE transactions on neural systems and rehabilitation engineering, 24(7), 774-783.

40. Serpen, G., \& Khan, R. H. (2018). Real-time Detection of Human Falls in Progress: Machine Learning Approach. Procedia Computer Science, 140, 238-247.

41. Shang, Y., Liu, Z., \& Wang, J. (2014). Posture recognition for the elderly based on wireless sensor networks. In The 26th Chinese Control and Decision Conference (2014 CCDC), 2496-2499.

42. Sierra-Correa, P. C., \&Kintz, J. R. C. (2015). Ecosystem-based adaptation for improving coastal planning for sea-level rise: A systematic review for mangrove coasts. Marine Policy, 51, 385-393.

43. Sixsmith, A., \& Johnson, N. (2004). A smart sensor to detect the falls of the elderly. IEEE Pervasive computing, 3(2), 42-47.

44. Soewito, B., Irwan, A. A., \&Gunawan, F. E. (2015). Fall detection algorithm to generate security alert. Procedia Computer Science, 59(Supplement C), 350-356.

45. Stone, E. E., \&Skubic, M. (2014). Fall detection in homes of older adults using the Microsoft Kinect. IEEE Journal of biomedical and health informatics, 19(1), 290-301.

46. Sumiya, T., Matsubara, Y., Nakano, M., \&Sugaya, M. (2015). A mobile robot for fall detection for elderly-care. Procedia computer science, 60, 870-880.

47. Suryadevara, N. K., \& Mukhopadhyay, S. C. (2012). Wireless sensor network based home monitoring system for wellness determination of elderly. IEEE Sensors Journal, 12(6), 1965-1972.

48. Taniguchi, Y., Nakajima, H., Tsuchiya, N., Tanaka, J., Aita, F., \&Hata, Y. (2014). A falling detection system with plural thermal array sensors. In 2014 Joint 7th International Conference on Soft Computing and Intelligent Systems (SCIS) and 15th International Symposium on Advanced Intelligent Systems (ISIS), 673-678.

49. Tinetti, M. E. (1994). Prevention of falls and fall injuries in elderly persons: a research agenda. Preventive medicine, 23(5), 756-762.

50. Tinetti, M. E., \& Williams, C. S. (1997). Falls, injuries due to falls, and the risk of admission to a nursing home. New England journal of medicine, 337(18), 1279-1284.

51. Mirkin, B., \& Weinberger, M.B. (2001). The demography of population ageing. publicadoen Population Bulletin of the United Nations, 2(43), 37-53.

52. United Nations. (2005). Living arrangements of older persons around the world. New York: United Nations, Department of Economic and Social Affair, Population Division, 240, 1-164.

53. Vaportzis, E., Giatsi Clausen, M., \&Gow, A. J. (2017). Older adults perceptions of technology and barriers to interacting with tablet computers: a focus group study. Frontiers in Psychology, 8, 1687.

54. Yacchirema, D., de Puga, J. S., Palau, C., \&Esteve, M. (2018). Fall detection system for elderly people using IoT and big data. Procedia computer science, 130, 603-610. 
55. Yang, L., Ren, Y., \& Zhang, W. (2016). 3D depth image analysis for indoor fall detection of elderly people. Digital Communications and Networks, 2(1), 24-34.

56. Yodpijit, N., Sittiwanchai, T., \&Jongprasithporn, M. (2017, April). The development of Artificial Neural Networks (ANN) for falls detection. In 2017 3rd International Conference on Control, Automation and Robotics (ICCAR), 547-550.

57. Yu, X. (2008). Approaches and principles of fall detection for elderly and patient. In HealthCom 200810th International Conference on e-health Networking, Applications and Services, 42-47.

58. Zarit, S. H., Reever, K. E., \& Bach-Peterson, J. (1980). Relatives of the impaired elderly: correlates of feelings of burden. The gerontologist, 20(6), 649-655.

59. Zhang, Z., Conly, C., \&Athitsos, V. (2015). A survey on vision-based fall detection. In Proceedings of the 8th ACM international conference on Pervasive technologies related to assistive environments, 1-7.

60. Zheng, J., Zhang, G., \& Wu, T. (2009). Design of automatic fall detector for elderly based on triaxial accelerometer. In 2009 3rd International Conference on Bioinformatics and Biomedical Engineering, 14. 